\title{
PENGGUNAAN BAHAN BANTU MENGAJAR GURU MATEMATIK SEKOLAH RENDAH
}

\author{
${ }^{1}$ Mohd Suhaimi Bin Omar, ${ }^{2}$ Noor Shah Saad, ${ }^{3}$ Mohd. Uzi Dollah \\ 1,2,3Fakulti Pembangunan Manusia, \\ Universiti Pendidikan Sultan Idris
}

\begin{abstract}
Abstrak
Kajian ini dijalankan untuk mengenal pasti tahap kekerapan penggunaan bahan bantu mengajar dalam kalangan guru matematik. Kajian ini juga bertujuan mengenal pasti persepsi guru matematik terhadap penggunaan bahan bantu mengajar, kekangan dan cabaran yang dihadapi oleh mereka dalam penggunaan bahan bantu mengajar. Responden kajian ini terdiri daripada 70 orang guru matematik dari 20 buah sekolah rendah di Daerah Batang Padang, Perak. Kajian ini menggunakan kaedah tinjauan yang melibatkan kerja peninjauan kuantitatif dan penafsiran kualitatif. Instrumen yang digunakan adalah soal selidik. Satu set borang soal selidik telah diedarkan kepada responden untuk mendapatkan maklumat dan data yang diperlukan. Segala data yang diperolehi dianalisis menggunakan perisian komputer 'Statistical Package For Social Science SPSS versi 22' untuk mendapatkan kekerapan, peratus dan min. Dapatan kajian menunjukkan bahawa tahap penggunaan alat bantu mengajar dalam kalangan guru-guru matematik adalah tinggi. Selain itu, dapatan kajian juga menunjukkan persepsi guru terhadap penggunaan bahan bantu mengajar juga adalah positif. Manakala hasil analisis juga menunjukkan terdapat kekangan dan cabaran yang dihadapi oleh guru dalam penggunaan bahan bantu mengajar. Beberapa cadangan juga dikemukakan untuk mempertingkatkan tahap penggunaan bahan bantu mengajar dalam pengajaran matematik. Kesimpulan daripada kajian mengambarkan bahawa penggunaan bahan bantu mengajar adalah penting bagi guru-guru untuk membantu mereka dalam proses pengajaran dan pembelajaran. Implikasi kajian juga menunjukkan penggunaan bahan bantu mengajar bukan sahaja memberi faedah kepada guru, malahan ianya juga memberi impak yang besar kepada murid - murid.
\end{abstract}

Kata kunci Bahan bantu mengajar, persepsi, kekangan dan cabaran.

\begin{abstract}
This study was conducted to identify the level of frequency using of teaching aids among mathematics teachers. This study also aims to identify the mathematical teacher perceptions towards the use of teaching aids, restraints and challenges faced by them in the use of teaching aids. The respondents of this study consists of 70 teachers of mathematics from 20 primary schools in the District of Batang Padang, Perak. This study used a survey method that involves the review of quantitative and qualitative interpretation. The instrument used was a questionnaire. A
\end{abstract}


set of questionnaires were distributed to the respondents to obtain the necessary information and data. All data were analyzed using computer software Statistical Package for Social Sciences SPSS version 22 'to get the frequency, percentage and mean. The results showed that the use of teaching aids in mathematics among teachers is high. In addition, the study also shows that the perception of teachers to use teaching aids are also positive. While the results of the analysis also shows that there are constraints and challenges faced by teachers in the use of teaching aids. A few suggestions are given to increase the use of teaching aids in the teaching of mathematics. Conclusions from the study reflects that the use of teaching aids is important for teachers to assist them in the process of teaching and learning. The study also demonstrates the use of teaching aids not only benefit the teachers, but they also have a major impact towards pupils.

Keywords Teaching aids, perceptions, constraints and challenges.

\section{PENGENALAN}

Salah satu bidang ilmu yang luas dan sentiasa berkait rapat dengan aktiviti kehidupan seharian kita adalah ilmu matematik, di mana ia boleh berlaku sama ada kita sedar atau sebaliknya. Penekanan terhadap konsep, fakta, kemahiran mengira dan menyelesaikan masalah adalah intipati utama pendidikan matematik. Kepintaran yang ada pada manusia akan dapat dipertingkatkan dengan adanya ilmu matematik dengan tujuan untuk menyelesaikan masalah harian dan juga sebagai alat untuk membangunkan potensi diri individu. Matematik biasanya dianggap sebagai suatu mata pelajaran yang abstrak dan memerlukan pelajar-pelajar yang boleh berfikir secara sistematik dan mantik. Oleh itu, bagi merealisasikan kepentingan matematik dalam dunia pendidikan Malaysia, Kurikulum Standard Sekolah Rendah (KSSR) dan Kurikulum Standard Sekolah Menengah (KSSM) telah diwujudkan dengan menjadikan matematik sebagai komponen wajib yang perlu dipelajari oleh semua pelajar. Bersesuaian dengan sukatan Matematik di peringkat sekolah rendah yang menjadikan matematik sebagai satu subjek teras yang menekankan lebih dari satu kemahiran. Antara kemahiran yang perlu untuk menguasai matematik adalah kemahiran mengira, menaakul, pemahaman konsep, menyelesaiakan masalah dan juga kemahiran bahasa matematik. Turut diterapkan adalah nilai- nilai murni dan juga kemanusiaan.

Peredaran zaman yang begitu pesat pada masa kini sedikit sebanyak telah merubah landskap pengajaran dan pembelajaran matematik. Penggunaan kaedah tradisional seperti kapur tulis dan papan hitam sudah tidak lagi releven dengan peekembangan pendidikan semasa. Lambakan teknologi dalam pendidikan yang menyediakan pelbagai platform kepada murid seharusnya menjadi pilihan utama guru-guru. Namun, penggunaan teknologi semata-mata buakanlah jaminan kepada keberkesanan sesuatu pengajaran. Teras utama pengajaran matematik adalah pemahaman konsep. Oleh itu adalah sangat penting bagi guru-guru untuk menerapkan penggunaan bahan bantu mengajar semasa sesi pengajaran dan pembelajaran mereka. 
Hal ini adalah penting bagi memastikan murid bukan sahaja memahami isi pelajaran yang disampaikan, malah penggunaan bahan bantu mengajar juga akan berperanan untuk menarik minat murid.

Hakikatnya, setiap murid mempunyai kecerdasan dan kemahiran tersendiri yang diwarisi mereka sejak dilahirkan. Kecerdasan dan kemahiran ini adalah aset penting bagi mereka untuk belajar dan mengadaptasi diri mereka dengan persekitaran. Umumnya diketahui bahawa pembelajaran bukan sahaja memerlukan guru yang baik, malah ransangan dan kecerdasan amatlah diperlukan. Murid akan mengaplikasikan segala maklumat dan rangsangan di sekitar mereka untuk dijadikan panduan kepada mereka untuk membina sesuatu pengetahuan atau pengalaman baru. Oleh itu, guru perlulah memainkan peranan mereka dengan sebaik mungkin dalam mentadbir dan mengurus bahan bantu mengajar yang akan mereka gunakan. Hal ini kerana, bahan bantu yang digunakan akan bertindak sebagai media yang akan merangsang dan mengembangkan pengetahuan dan kecerdasan murid mereka. Pemilihan bahan dan media yang bersesuaian juga penting untuk memastikan murid selesa dan seronok untuk belajar. Selain itu guru juga harus peka dan berinovatif dalam merancang aktiviti pengajaran mereka supaya sesuai dengan bahan dan tahap murid yang akan mereka ajar, kerana kesepaduan antara teknik, bahan dan aktiviti akan dapat memberi impak yang lebih baik terhadap pemahaman dan persepsi murid.

Umumnya, guru-guru percaya bahawa tahap kefahaman dan penguasaan murid dalam sesuatu topik pelajaran adalah banyak dibantu oleh penggunaan bahan bantu mengajar (Noraziah Abd. Hamid, 1981). Oleh itu, guru-guru perlulah berusaha untuk memenuhi keperluan dan kebolehan murid-murid dengan memilih bahan bantu mengajar dari pelbagai sumber. Mat Nor Hussein dan Abd. Rahman Rashid (1989) turut menyatakan bahawa setiap media pengajaran semestinya mempunyai daya interaksi yang berbeza dan ianya perlu diteliti dan difahami oleh setiap guru supaya bahan media tersebut dapat memenuhi prinsip-prinsip penggunaan bahan bantu mengajar yang sepatutnya dan sekaligus akan dapat menghasilkan impak yang maksimum semasa digunakan. Oleh itu bahan bantu mengajar yang mempunyai daya interaksi yang baik dengan murid akan mampu untuk menjadi panduan kepada mereka untuk memperolehi pengalaman belajar yang maksimum bagi memperkembangkan bukan sahaja intelektual malahan dari aspek sosial, emosi dan daya penghargaan mereka. Hakikatnya adalah sangat jelas bahawa murid-murid akan lebih mudah untuk menguasai sesuatu kemahiran matematik sekiranya guru dapat memilih dan menggunakan bahan bantu mengajar yang sesuai. Bertepatan dengan dasar dasar kurikulum yang baharu iaitu dasar Kurikulum Standard Sekolah Rendah (KSSR), yang lebih menekankan penguasaan kemahiran-kemahiran asas seperti kemahiran numerasi sebelum murid memasuki tahap dua disekolah rendah, (KPM, 2012).

Selain itu, proses pengajaran dan pembelajaran juga akan lebih lancar dan berkualiti dengan adanya penggunaan bahan bantu mengajar. Tambahan pula, dengan mengaplikasikan bahan bantu mengajar, murid-murid akan lebih berminat dan memberi tumpuan terhadap pelajaran. Kajian Hassan (1993), mendapati bahawa penggunaan bahan bantu mengajar memberikan lebih banyak kesan positif terhadap proses pengajaran dan pembelajaran dan kesan-kesan positif tersebut adalah seperti berikut: 
a. Melancarkan proses pengajaran dan pembelajaran

b. Menjimatkan masa dan tenaga.

c. Mengelakkan murid berasa jemu dan bosan.

d. Memberikan impak yang maksimun dengan penggunaan masa yang minimum.

Menurut Hamalik (1986), minat dan keinginan untuk belajar dalam kalangan murid dapat dibangkitkan dengan adanya bahan bantu mengajar semasa proses pengajaran dilaksanakan dan keadaan ini juga turut mempengaruhi motivasi yang seterusnya akan menjadikan murid aktif sekaligus memberikan kesan positif terhadap murid. Penggunaan bahan bantu mengajar yang selari dengan topik yang diajar akan memberikan kelebihan kepada guru untuk meningkatkan semangat murid sepanjang proses pengajaran dan pembelajaran berlansung. Pendek kata sesi pembelajaran yang pasif akan membuatkan murid bosan dan ini akan menyebabkan murid hilang fokus dan mengantuk, dan mereka juga akan melakukan aktiviti lain. Dapatan ini juga adalah selari dengan dapatan kajian Mohd Dahlan (1992), yang menyatakan bahawa murid-murid akan lebih berminat dan fokus terhadap pelajaran sekiranya bahan bantu mengajar dapat divariasikan dan digunakan dengan cara yang bersesuaian. Selain itu, konsep dan kemahiran asas matematik dapat disampaikan dengan lebih mudah melalui pengunaan bahan bantu mengajar. Manakala Omardin Ashaari (1999), berpendapat bahawa dengan penggunaan pelbagai bahan bantu mengajar, masalah-masalah dan kaedah pengajaran guru yang sentiasa berubah mengikut peredaran zaman juga mampu ditangani.

Kesimpulannya, bidang pendidikan matematik adalah salah satu subjek yang penting dalam kehidupan seharian kita, juga menjadi penggerak utama kepada perkembangan sains dan teknologi. Malah untuk seseorang individu berjaya dalam alam pekerjaan dan berfungsi dalam masyarakat, mereka juga perlu memahami dan menggunakan ilmu dan falsafah matematik. Walaupun begitu, sikap dan persepsi masyarakat yang negatif terhadap matematik telah menyebabkan ramai murid-murid yang mengangap matematik sebagai satu matapelajaran yang sukar. Keadaan ini terjadi mungkin disebabkan oleh sifat matematik yang memerlukan murid untuk memahami pelbagai bentuk, simbol, dan rumus yang banyak untuk menguasainya. Oleh itu, salah satu cara yang akan dapat menarik minat murid untuk lebih dekat dengan matematik adalah melalui penggunaan bahan-bahan manipulatif atau bahan bantu mengajar, terutamanya bagi murid-murid tahap satu diperingkat sekolah rendah.

\section{METODOLOGI KAJIAN}

Kajian ini berbentuk deskriptif dan ia bertujuan untuk menganalisis penggunaan bahan bantu mengajar guru matematik sekolah rendah di daerah Batang Padang. Bagi menjalankan kajian ini, kaedah tinjauan yang memerlukan kerja-kerja peninjauan kuantitatif dan penafsiran kuantitatif telah digunakan. Populasi kajian ini tertumpu kepada 64 sekolah di daerah Batang Padang yang merangkumi 11 buah Sekolah Jenis Kebangsaan Tamil (SJKT), 35 buah Sekolah Kebangsaan 
(SK) dan 52 buah Sekolah Jenis Kebangsaan Cina (SJKC). Daripada jumlah itu, sebanyak 20 buah sekolah telah dipilih sebagai sampel kajian yang terdiri daripada 70 orang guru matematik.

Data premier bagi kajian ini telah dikumpul melalui kajian lapangan, iaitu dengan menggunakan set borang soal selidik sebagai instrument utama kajian. Set soal selidik yang digunakan dalam kajian ini dibahagikan kepada empat bahagian iaitu Bahagian A dan Bahagian B, Bahaian C dan Bahagian D. Bahagian A mengandungi item-item yang berkaitan dengan latar belakang responden seperti jantina, umur, bangsa, jenis sekolah dan pengalaman mengajar matematik. Responden perlu mengisi maklumat yang dikehendaki pada ruang yang disediakan. Bahagian $\mathrm{B}$ adalah tentang penggunaan bahan bantu mengajar dan Bahagian $C$ dan Bahagian D adalah tentang persepsi dan kekangan serta cabaran dalam penggunaan bahan bantu mengajar yang masing - masing mengandungi 15 dan 10 item.

Jadual 1 Bilangan Item Bagi Setiap Kategori Penggunaan BBM

\begin{tabular}{clc}
\hline Bahagian & \multicolumn{1}{c}{ Perkara } & Jumlah Soalan \\
\hline A & Latar belakang responden & 5 \\
B & Peratusan penggunaan BBM responden & 55 \\
C & Persepsi guru terhadap BBM & 15 \\
D & Kekangan dan cabaran dalam penggunaan & 10 \\
\hline
\end{tabular}

Dalam kajian ini, soal selidik berskala lima mata dan empat mata dipilih dan responden kajian perlu memilih jawapan paling sesuai dengan pilihan diri. Soal selidik lima mata dipilih bagi menentukan kekerapan penggunaan bahan bantu mengajar (BBM). Manakala soal selidik empat mata digunakan untuk menentukan persepsi serta kekangan dan cabaran yang dihadapi oleh guru bagi menggunakan bahan bantu mengajar (BBM). Jadual 2 dan Jadual 3 di bawah menunjukkan skala yang digunakan.

Jadual 2 Jadual Skala Likert Lima Mata

\begin{tabular}{ccc}
\hline Peringkat & Singkatan & Skor \\
\hline Amat Kerap & AK & 5 \\
Kerap & K & 4 \\
Kadang Kala & KL & 3 \\
Jarang & J & 2 \\
Tidak Pernah & TP & 1 \\
\hline
\end{tabular}

Jadual 2 menunjukkan skala likert lima mata yang digunakan bagi menentukan kekerapan penggunaan BBM dikalangan responden. 
Jadual 3 Jadual Skala Likert Empat Mata

\begin{tabular}{ccc}
\hline Peringkat & Singkatan & Skor \\
\hline Sangat Setuju & SS & 4 \\
Setuju & S & 3 \\
Tidak Setuju & TS & 2 \\
Sangat Tidak Setuju & STS & 1 \\
\hline
\end{tabular}

Jadual 3 menunjukkan skala likert empat mata yang digunakan bagi menentukan persepsi dan kekangan serta cabaran yang dihadapi responden dalam penggunaan BBM.

\section{DAPATAN KAJIAN DAN PERBINCANGAN}

\section{Demografi}

Bahagian dapatan dan perbincangan akan membincangkan dapatan kajian tentang maklumat yang telah dikumpul. Bagi maklumat demografi resonden, faktor demografi yang dibincangkan adalah jantina, bangsa, jenis sekolah, pengalaman mengajar dan opsyen guru.

Hasil analisis data menunjukkan bilangan responden lelaki adalah seramai 30 orang $(42.9 \%)$, manakala 40 orang $(57.1 \%)$ adalah perempuan. Responden bagi kajian ini terdiri daripada 3 bangsa utama iaitu 41 orang (58.6\%) adalah Melayu, 15 orang (21.4\%) adalah Cina dan 14 (20.0\%)adalah dari bangsa India. Manakala bagi jenis sekolah pula, 20 buah sekolah telah terlibat dalam kajian ini yang terdiri daripada tiga jenis sekolah iaitu 40 orang (57.1\%) adalah dari Sekolah Kebangsaan, 16 orang (22.9\%) adalah dari Sekolah Jenis Kebangsaan Cina dan selebihnya iaitu seramai 14 orang $(20.0 \%)$ adalah dari Sekolah Jenis Kebangsaan Tamil.

Selain itu analisis data juga menunjukkan, guru yang mengajar 0 hingga 2 tahun adalah 4 orang (5.7\%), guru yang mengajar 2 hingga 5 tahun adalah 8 orang (11.4\%), guru yang mengajar 5 hingga 10 tahun adalah 27 orang $(38.6 \%)$, guru yang mengajar 10 hingga 15 tahun adalah 17 orang (24.3\%) dan guru yang mengajar lebih dari 15 tahun adalah 14 orang $(20.0 \%)$ dan secara keseluruhannya, responden yang terlibat dengan kajian ini adalah dari opsyen matematik iaitu seramai 68 orang (97.1\%) dan guru bukan dari opsyen matematik adalah seramai 2 orang $(2.9 \%)$.

\section{Kekerapan Penggunaan Bahan Bantu Mengajar Matematik Oleh Guru-Guru Di Sekolah Rendah}

Bahagian ini melaporkan analisis kekerapan responden meggunakan bahan bantu mengajar (BBM) dalam 11 topik utama subjek matematik tahap 1. Melalui penggunaan skala likert lima gred ini, data-data yang diperolehi dianalisis dan dinyatakan mengikut bilangan, peratus dan min. 
Jadual 4 Analisis Min Mengikut Topik Penggunaan BBM Di kalangan Guru Matematik Sekolah Rendah Daerah Batang Padang, Perak

\begin{tabular}{cccc}
\hline Bil & Perkara & Min & $\begin{array}{c}\text { Tahap } \\
\text { Penggunaan }\end{array}$ \\
\hline
\end{tabular}

\begin{tabular}{|c|c|c|c|}
\hline & Topik Nombor Bulat & & \\
\hline 1 & Pembilang & 4.99 & Sangat Tinggi \\
\hline 2 & Carta Nilai tempat & 4.14 & Sangat Tinggi \\
\hline 3 & Blok Asas 10 & 3.97 & Tinggi \\
\hline 4 & Abakus & 4.06 & Sangat Tinggi \\
\hline \multirow[t]{2}{*}{5} & Kalkulator & 3.37 & Tinggi \\
\hline & Topik Pecahan & & \\
\hline 6 & Jalur kertas & 4.73 & Sangat Tinggi \\
\hline 7 & Rod kuisinari & 3.96 & Tinggi \\
\hline 8 & Lipatan Kertas & 4.19 & Sangat Tinggi \\
\hline 9 & Bulatan pecahan (Fraction circle) & 4.57 & Sangat Tinggi \\
\hline \multirow[t]{2}{*}{10} & Kit Pecahan & 4.47 & Sangat Tinggi \\
\hline & Topik perpuluhan & & \\
\hline 11 & Kad Imbasan & 4.26 & Sangat Tinggi \\
\hline 12 & Petak seratus & 4.39 & Sangat Tinggi \\
\hline 13 & Carta nilai tempat perpuluhan & 4.69 & Sangat Tinggi \\
\hline 14 & Blok Dienes & 3.37 & Tinggi \\
\hline \multirow[t]{2}{*}{15} & Kad Jalur perpuluhan (decimals strips) & 4.10 & Sangat Tinggi \\
\hline & Topik peratus & & \\
\hline 16 & Petak seratus & 4.40 & Sangat Tinggi \\
\hline 17 & Papan gulung berpetak & 4.30 & Sangat Tinggi \\
\hline 18 & Blok Dienes & 3.34 & Tinggi \\
\hline 19 & Rantai Manik 100 (Hundred beads) & 2.91 & Sederhana \\
\hline \multirow[t]{2}{*}{20} & Bulatan 100 (Hunderd disk) & 3.36 & Tinggi \\
\hline & Topik wang & & \\
\hline 21 & Wang syiling contoh & 4.67 & Sangat Tinggi \\
\hline 22 & Wang kertas contoh & 4.14 & Sangat Tinggi \\
\hline 23 & Contoh resit pembelian & 3.60 & Tinggi \\
\hline 24 & Permainan monopoli & 4.34 & Sangat Tinggi \\
\hline \multirow[t]{2}{*}{25} & Katalog harga barang & 4.20 & Sangat Tinggi \\
\hline & Topik masa dan waktu & & \\
\hline 26 & Model muka jam & 5.00 & Sangat Tinggi \\
\hline 27 & Jam digital & 4.43 & Sangat Tinggi \\
\hline 28 & Jam randik & 4.01 & Sangat Tinggi \\
\hline 29 & $\begin{array}{l}\text { Jadual (jadual kelas, jadual perjalanan, pro- } \\
\text { gram television) }\end{array}$ & 4.43 & Sangat Tinggi \\
\hline
\end{tabular}


30 Kalendar

\section{Topik panjang}

Alat ukuran tidak piawai (klip kertas, benang, anggota badan)

32 Pita ukur

33 Pembaris sentimeter

34 Pembaris meter

35 Rodo meter

\section{Topik jisim}

36 Kad Imbasan

37 Neraca dua lengan (balancing)

38 Neraca spring

39 Neraca mampatan

40 Alat penimbang elektronik

\section{Topik isipadu cecair}

41

Alat penyukat tidak piawai (baldi, botol, cawan)

42 Silinder penyukat

43 Bikar

44 Kelalang kon

45 Jug penyukat bersengat

\section{Topik bentuk dan ruang}

46 Objek sebenar (Realia)

47 Papan geometri

48 Tangram

49 Model Bungkah dua atau tiga matra

50 Set geometri

\section{Topik Data}

51 Dadu

52 Carta (palang, pie)

53 Piktograf

54 Gundalan (lidi, batang aiskrim)

55 Jadual dan Gambarajah
5.00

Sangat Tinggi

5.00

4.80

4.80

2.70

4.04

3.64

4.90

2.57

5.00

4.36

4.77

2.71

3.26

4.80

4.26

4.43

4.67

4.17

4.74

4.93

4.93

4.63

4.86

4.21
Sangat Tinggi

Sangat Tinggi

Sangat Tinggi

Sangat Tinggi

Sederhana

Tinggi

Sangat Tinggi

Tinggi

Sangat Tinggi

Sederhana

Sangat Tinggi

Sangat Tinggi

Sangat Tinggi

Sederhana

Tinggi

Sangat Tinggi

Sangat Tinggi

Sangat Tinggi

Sangat Tinggi

Sangat Tinggi

Sangat Tinggi

Sangat Tinggi

Sangat Tinggi

Sangat Tinggi

Sangat Tinggi

Sangat Tinggi

Jadual 4 menunjukkan 55 item yang disediakan bagi mengukur tahap kekerapan penggunaan bahan bantu mengajar. Didapati sebanyak empat item mendapat skor min kurang daripada nilai 3.0, iaitu berada pada tahap penggunaan yang sederhana dan item tersebut adalah rantai manik, rodo meter, alat penimbang elektronik, dan kelalang kon. Ini menunjukkan guru matematik jarang menggunakan BBM tersebut dalam proses pengajaran mereka. Selain itu terdapat sepuluh item 
mendapat skor min kurang daripada nilai 4.0 dan item tersebut adalah blok asas 10, kalkulator, rod kuisinari, blok deines, bulatan 100, contoh resit pembelian, kad imbasan, neraca spring dan jug penyukat bersengat. Ini menunjukkan tahap penggunaan bahan bantu mengajar tersebut adalah berada pada tahap yang tinggi.

Walau bagaimanapun, secara keseluruhannya tahap penggunaan bahan bantu mengajar di kalangan guru matematik di daerah Batang Padang adalah berada pada tahap yang sangat tinggi dengan skor min keseluruhan $=4.21$, yang menunjukkan penggunaan bahan bantu mengajar adalah kerap digunakan.

\section{Persepsi Guru-Guru Terhadap Penggunaan Bahan Bantu Mengajar (BBM) Matematik Di Sekolah Rendah}

Setelah data yang diperolehi dari soal selidik yang disediakan, analisis data menunjukkan persepsi guru-guru matematik terhadap penggunaan bahan bantu mengajar adalah positif. Jadual 4 menunjukkan butiran lengkap bagi hasil analisis yang dijalankan.

Jadual 5 Analisis Min, Bilangan Dan Peratus Persepsi Terhadap Penggunaan BBM Dalam Kalangan Guru Matematik Sekolah Rendah Daerah Batang Padang, Perak.

\begin{tabular}{|c|c|c|c|c|c|c|}
\hline Bil & Perkara & Min & STS & TS & $\mathbf{S}$ & SS \\
\hline 1 & $\begin{array}{l}\text { Penggunaan BBM adalah } \\
\text { sangat penting untuk } \\
\text { meningkatkan kefahaman } \\
\text { murid tentang konsep } \\
\text { matematik }\end{array}$ & 4 & & & & $\begin{array}{c}70 \\
100 \%\end{array}$ \\
\hline 2 & $\begin{array}{l}\text { Penggunaan BBM adalah } \\
\text { sangat penting untuk menarik } \\
\text { minat murid terhadap } \\
\text { pembelajaran matematik }\end{array}$ & 3.94 & & & $\begin{array}{c}4 \\
5.7 \%\end{array}$ & $\begin{array}{c}66 \\
94.3 \%\end{array}$ \\
\hline 3 & $\begin{array}{l}\text { Penggunaan BBM adalah } \\
\text { sangat penting untuk } \\
\text { meningkatkan penglibatan } \\
\text { murid dalam aktiviti PdP di } \\
\text { dalam kelas }\end{array}$ & 3.94 & & & $\begin{array}{c}4 \\
5.7 \%\end{array}$ & $\begin{array}{c}66 \\
94.3 \%\end{array}$ \\
\hline 4 & $\begin{array}{l}\text { Penggunaan BBM adalah } \\
\text { sangat penting untuk } \\
\text { memupuk perasaan ingin tahu } \\
\text { murid }\end{array}$ & 3.94 & & & $\begin{array}{c}4 \\
5.7 \%\end{array}$ & $\begin{array}{c}66 \\
94.3 \%\end{array}$ \\
\hline 5 & $\begin{array}{l}\text { Penggunaan BBM adalah } \\
\text { cara yang menyeronokkan } \\
\text { dan mudah untuk } \\
\text { memperkenalkan dan } \\
\text { menggambarkan konsep } \\
\text { matematik. }\end{array}$ & 3.94 & & & $\begin{array}{c}4 \\
5.7 \%\end{array}$ & $\begin{array}{c}66 \\
94.3 \%\end{array}$ \\
\hline
\end{tabular}




\begin{tabular}{|c|c|c|c|c|}
\hline 6 & $\begin{array}{l}\text { Penggunaan BBM dalam } \\
\text { pengajaran matematik akan } \\
\text { membantu murid belajar } \\
\text { untuk mengaitkan situasi } \\
\text { dunia sebenar dengan simbol } \\
\text { matematik }\end{array}$ & 3.94 & $\begin{array}{c}4 \\
5.7 \%\end{array}$ & $\begin{array}{c}66 \\
94.3 \%\end{array}$ \\
\hline 7 & $\begin{array}{l}\text { Penggunaan BBM membawa } \\
\text { kepada sikap murid yang } \\
\text { lebih baik terhadap matematik }\end{array}$ & 3.97 & $\begin{array}{c}2 \\
2.9 \%\end{array}$ & $\begin{array}{c}68 \\
97.1 \%\end{array}$ \\
\hline 8 & $\begin{array}{l}\text { Penggunaan BBM dalam } \\
\text { pengajaran dan pembelajaran } \\
\text { matematik tidak dikhususkan } \\
\text { untuk aktiviti-aktiviti } \\
\text { pemulihan sahaja }\end{array}$ & 3.64 & $\begin{array}{c}25 \\
35.7 \%\end{array}$ & $\begin{array}{c}45 \\
64.3\end{array}$ \\
\hline 9 & $\begin{array}{l}\text { Penggunaan BBM dalam } \\
\text { pengajaran dan pembelajaran } \\
\text { matematik bukan hanya } \\
\text { sesuai untuk murid-murid } \\
\text { tahap 1 sahaja }\end{array}$ & 3.63 & $\begin{array}{c}26 \\
37.1 \%\end{array}$ & $\begin{array}{c}44 \\
62.9 \%\end{array}$ \\
\hline 10 & $\begin{array}{l}\text { Penggunaan BBM dalam } \\
\text { pengajaran dan pembelajaran } \\
\text { matematik tidak memberi } \\
\text { kesan negatif ke atas } \\
\text { pembelajaran murid }\end{array}$ & 3.60 & $\begin{array}{c}28 \\
40 \%\end{array}$ & $\begin{array}{c}42 \\
60 \%\end{array}$ \\
\hline 11 & $\begin{array}{l}\text { Penggunaan BBM dalam } \\
\text { pengajaran dan pembelajaran } \\
\text { matematik adalah lebih } \\
\text { menjimatkan masa }\end{array}$ & 3.67 & $\begin{array}{c}23 \\
32.9 \%\end{array}$ & $\begin{array}{c}47 \\
67.1 \%\end{array}$ \\
\hline 12 & $\begin{array}{l}\text { Penggunaan BBM bukan } \\
\text { faktor guru hilang kawalan di } \\
\text { dalam kelas }\end{array}$ & 3.60 & $\begin{array}{c}28 \\
40 \%\end{array}$ & $\begin{array}{c}42 \\
60 \%\end{array}$ \\
\hline 13 & $\begin{array}{l}\text { Penggunaan BBM tidak akan } \\
\text { menyebabkan suasana kelas } \\
\text { menjadi bising dan kucar- } \\
\text { kacir }\end{array}$ & 3.64 & $\begin{array}{c}25 \\
35.7 \%\end{array}$ & $\begin{array}{c}45 \\
64.3\end{array}$ \\
\hline 14 & $\begin{array}{l}\text { Penggunaan BBM tidak } \\
\text { memerlukan guru perlu } \\
\text { bekerja lebih masa bagi } \\
\text { membina BBM }\end{array}$ & 3.64 & $\begin{array}{c}25 \\
35.7 \%\end{array}$ & $\begin{array}{c}45 \\
64.3\end{array}$ \\
\hline 15 & $\begin{array}{l}\text { Penggunaan BBM tidak } \\
\text { memerlukan masa pengajaran } \\
\text { yang lebih panjang }\end{array}$ & 3.60 & $\begin{array}{c}28 \\
40 \%\end{array}$ & $\begin{array}{c}42 \\
60 \%\end{array}$ \\
\hline & Purata Min & 3.78 & & \\
\hline
\end{tabular}

Jadual 5 menunjukkan 15 item yang disediakan bagi mengukur persepsi guru terhadap penggunaan bahan bantu mengajar. Pada keseluruhannya skor min persepsi 
guru terhadap penggunaan BBM adalah tinggi iaitu berada antara nilai 3.60 hingga 4.00. Skor min keseluruhan persepsi guru adalah 3.78. Nilai min paling rendah ialah 3.60, iaitu item 10 (Penggunaan BBM dalam pengajaran dan pembelajaran matematik tidak memberi kesan negatif ke atas pembelajaran murid), item 12 (Penggunaan BBM bukan faktor guru hilang kawalan di dalam kelas) dan item 15 (Penggunaan BBM tidak memerlukan masa pengajaran yang lebih panjang). Manakala nilai min paling tinggi adalah 4.00 iaitu item 1 (Penggunaan BBM adalah sangat penting untuk meningkatkan kefahaman murid tentang konsep matematik). Secara keseluruhannya purata nilai min ialah 3.78, iaitu berada pada tahap persetujuan yang tinggi. Ini menunjukkan bahawa secara umumnya semua responden mempunyai persepi yang baik terhadap penggunaan bahan bantu mengajar (BBM).

\section{Kekangan Dan Cabaran Yang Dihadapi Oleh Guru Dalam Penggunaan Bahan Bantu Mengajar Untuk Mengajar Mata Pelajaran Matematik Di Sekolah Rendah}

Bahagian ini akan melaporkan analisis masalah-masalah dalam penggunaan bahan bantu mengajar (BBM). Kaedah analisis yang digunapakai adalah dengan menggunakan skor nilai min bagi setiap item yang dikemukakan kepada responden. Analisis data adalah seperti yang ditunjukkan dalam Jadual 6.

Jadual 6 Analisis Min, Bilangan Dan Peratusan Kekangan Serta Cabaran Penggunaan BBM Di Kalangan Guru Matematik Sekolah Rendah Daerah Batang Padang, Perak

\begin{tabular}{|c|c|c|c|c|c|c|}
\hline Bil & Perkara & Min & STS & TS & $\mathbf{S}$ & SS \\
\hline 1 & $\begin{array}{l}\text { Guru tidak mempunyai } \\
\text { masa yang mencukupi untuk } \\
\text { membina atau menyediakan } \\
\text { BBM. }\end{array}$ & 4.00 & & & & $\begin{array}{c}70 \\
100 \%\end{array}$ \\
\hline 2 & $\begin{array}{l}\text { Guru tidak dibekalkan dengan } \\
\text { panduan penggunaan BBM } \\
\text { yang mencukupi. }\end{array}$ & 3.06 & & & $\begin{array}{c}66 \\
94.3 \%\end{array}$ & $\begin{array}{c}4 \\
5.7 \%\end{array}$ \\
\hline 3 & $\begin{array}{l}\text { Pilihan dan variasi penggunaan } \\
\text { BBM adalah terhad }\end{array}$ & 3.50 & & & $\begin{array}{c}35 \\
50 \% \\
\end{array}$ & $\begin{array}{c}35 \\
50 \%\end{array}$ \\
\hline 4 & $\begin{array}{l}\text { Silibus pengajaran yang } \\
\text { banyak dan tekanan pihak } \\
\text { pentadbir untuk menghabiskan } \\
\text { silibus. }\end{array}$ & 3.74 & & & $\begin{array}{c}18 \\
25.7 \%\end{array}$ & $\begin{array}{c}52 \\
74.3 \%\end{array}$ \\
\hline 5 & $\begin{array}{l}\text { Penggunaan BBM berpotensi } \\
\text { mengelirukan murid jika } \\
\text { persembahan adalah secara } \\
\text { melulu dan tidak teratur. }\end{array}$ & 3.03 & & $\begin{array}{c}2 \\
2.9 \%\end{array}$ & $\begin{array}{c}64 \\
91.4 \%\end{array}$ & $\begin{array}{c}4 \\
5.7 \%\end{array}$ \\
\hline
\end{tabular}




\begin{tabular}{|c|c|c|c|c|c|c|}
\hline 6 & $\begin{array}{l}\text { Guru kurang pengalaman dan } \\
\text { kepakaran untuk menggunakan } \\
\text { BBM }\end{array}$ & 3.11 & & $\begin{array}{l}5 \\
7.1 \%\end{array}$ & $\begin{array}{c}52 \\
74.3 \%\end{array}$ & $\begin{array}{c}13 \\
18.6 \%\end{array}$ \\
\hline 7 & $\begin{array}{l}\text { Kos penyediaan BBM adalah } \\
\text { sangat tinggi }\end{array}$ & 2.44 & $\begin{array}{c}3 \\
4.3 \% \\
\end{array}$ & $\begin{array}{c}35 \\
50 \% \\
\end{array}$ & $\begin{array}{c}30 \\
42.9 \% \\
\end{array}$ & $\begin{array}{c}2 \\
2.9 \% \\
\end{array}$ \\
\hline 8 & $\begin{array}{l}\text { Saiz kelas yang terlalu besar } \\
\text { untuk menggunakan BBM }\end{array}$ & 3.19 & & $\begin{array}{c}1 \\
1.4 \% \\
\end{array}$ & $\begin{array}{c}54 \\
77.1 \% \\
\end{array}$ & $\begin{array}{c}15 \\
21.4 \% \\
\end{array}$ \\
\hline 9 & $\begin{array}{l}\text { Masa untuk menguji } \\
\text { keberkesanan penggunaan } \\
\text { sesuatu BBM adalah terhad. }\end{array}$ & 3.94 & & & $\begin{array}{c}4 \\
5.7 \%\end{array}$ & $\begin{array}{c}66 \\
94.3 \%\end{array}$ \\
\hline 10 & $\begin{array}{l}\text { Beban kerja guru terlalu } \\
\text { banyak menyebabkan guru } \\
\text { tidak dapat menyediakan BBM } \\
\text { di dalam kelas }\end{array}$ & 3.86 & & & $\begin{array}{c}10 \\
14.3 \%\end{array}$ & $\begin{array}{c}60 \\
85.7 \%\end{array}$ \\
\hline & Min Keseluruhan & 3.39 & & & & \\
\hline
\end{tabular}

Jadual 6 menunjukkan skor min bagi sepuluh item kekangan dan cabaran dalam penggunaan bahan bantu mengajar (BBM). Didapati skor min adalah diantara 2.44 hingga 4.00. Nilai skor min yang paling rendah adalah pada item 7 (Kos penyediaan BBM adalah sangat tinggi) iaitu dengan nilai 2.44. Manakala skor min paling tinggi adalah pada item 1 (Guru tidak mempunyai masa yang mencukupi untuk membina atau menyediakan BBM) dengan nilai min sebanyak 4.00. Secara keseluruhannya purata min menunjukkan nilai 3.39 iaitu pada aras persetujuan tinggi. Keadaan ini menunjukkan terdapat beberapa kekangan dan cabaran dalam penggunaan Bahan Bantu Mengajar dikalangan guru Matematik sekolah rendah di daerah Batang Padang.

\section{KESIMPULAN}

Dalam apa juga sesi pengajaran dan pembelajaran apa-apa sahaja mata pelajaran, sasaran guru adalah untuk mencapai objektif pembelajarannya. Selain itu, guru juga mengharapkan bahawa sesi pengajaran dan pembelajaran yang dirancang serta yang telah dilaksanakannya itu adalah berkesan serta mampu membantu meningkatkan kefahaman murid terutamanya berkaitan dengan topik yang diajarkan itu. Malahan, guru juga mahu agar murid dapat memahami konsep topik yang diajar serta mampu mengaplikasikannya dengan betul. Justeru, penggunaan bahan manipulatif merupakan jalan paling mudah untuk mencapai hasrat tersebut, terutamanya dalam proses pembelajaran matematik di kalangan murid-murid tahun 1, 2 dan 3. Dengan menggunakan bahan-bahan manipulatif ini, murid akan lebih memahami konsep sesuatu topik yang diajar oleh guru. Bahan manipulatif ini berperanan sebagai medium yang akan membantu guru meningkatkan kefahaman murid terhadap konsep-konsep matematik yang agak kompleks bagi murid-murid berumur 7 hingga 11 tahun.

Selain itu, penggunaan bahan manipulatif ini juga dapat membantu muridmurid menguasai Kemahiran Kognitif seperti dalam pengkelasan, konsep ruang, 
konsep nombor, melakukan proses sains dan membuat penyelesaian masalah. pengalaman secara terus yang dialami oleh seseorang membolehkan perkataan dan simbol memberi makna kepadanya. Sesuatu bahan dengan sendirinya tidak dapat menghasilkan sebarang perubahan terhadap pembelajaran, tetapi guru yang mahir menggunakan bahan itu boleh memberikan kesan yang berkekalan. Guru yang mahir menggunakan bahan pengajaran bukan sahaja seorang pelukis yang dapat mereka bahan pengajaran tetapi juga adalah pelukis yang boleh memahami perbezaan individu. Pelajar juga dapat memahami sesuatu konsep itu dengan jelas dan tepat kerana mereka dapat melihat secara terus terutamanya yang melibatkan pekara yang abstrak. Rasional alat bantu mengajar digunakan dalam proses pengajaran dan pembelajaran adalah untuk memperjelaskan lagi penyampaian maklumat agar tidak terlalu bersifat verbalistik, mengatasi keterbatasan ruang, mengatasi sifat pasif pelajar dan memberi rangsangan, mempersamakan pengalaman dan membangkitkan persepsi di kalangan pelajar.

Secara kesimpulannya, hasil kajian ini memberikan gambaran tentang penggunaan bahan bantu mengajar (BBM) di kalangan guru-guru mateamtik di sekolah rendah. Pandangan guru yang dipaparkan melalui respon mereka dalam soal selidik jelas menunjukkan bahawa secara keseluruhannya guru-guru mengaplikasikan bahan bantu mengajar didalam pengajaran mereka. Keadaan ini memberi implikasi kepada pihak pentadbiran sekolah agar sentiasa memberikan perhatian kepada keperluan penggunaan bahan bantu mengajar agar guru dan murid dapat menikmati faedah daripadanya. Ini juga akan dapat membantu murid dalam meningkatkan pencapaian akademik mereka dan seterusnya memupuk sikap positif dalam mempelajari setiap mata pelajaran. Selain itu, hasil kajian juga membuktikan bahawa akan sentiasa terdapat kekangan dan cabaran dalam apa jua yang dipraktikkan oleh guru dan keadaan ini juga berlaku dalam penggunaan bahan bantu mengajar. Kebanyakkan guru yang menjawab soal selidik memberi respond bahawa kekangan masa adalah perkara utama yang mereka sering hadapi, disamping cabaran-cabaran seperti silibus pengajaran yang terlalu banyak dan tekanan dari pihak pentadbir untuk menghabiskan silibus. Walau bagaimanapun dari persepsi positif yang ditunjukkan oleh pihak guru, penggunaan bahan bantu mengajar akan terus dipraktikkan di sekolah walau apa jua cabaran dan kekangan yang mereka hadapi. Keadaan ini adalah bagi memastikan setiap murid sentiasa mendapat pendidikan yang terbaik. Semoga hasil dapatan kajian ini dapat menjadi garis panduan bagi pihak-pihak tertentu untuk meningkatkan pencapaian akademik murid-murid.

\section{RUJUKAN}

Ary, D. Jacob, LC Dan Razavieh, A. (1990). Introduction To Research In Education. Forth Worth, Harcourt Brace Collage Publisher.

Chen H. W. (2006). Penggunaan Alat Bantu Mengajar (ABM) di kalangan guru pelatih (Kajian Sosial) di Sekolah Kebangsaan Pujut Coner Miri Sarawak. Kertas Ilmiah: Institut Perguruan Sarawak, Miri Sarawak. 
Chua, Yan Piaw (2006a). Kaedah Penyelidikan. Kuala Lumpur: Mc Graw Hill (Malaysia) Sdn.Bhd.

Dale, E. (1946). Audio-visual methods in teaching. New York: The Dryden Press.

Dale, Edgar. (1969). Audio-Visual Methods in Teaching, 3rd ed., Holt, Rinehart \& Winston, New York,p. 108.

Ee, Ah Meng. (1997). Pendidikan di Malaysia 1: Falsafah Pendidikan, Guru dan Sekolah. Shah Alam : Fajar Bakti.

Hamalik. (1986). Media Pendidikan. Bandung: Citra Aditya Bakti.

Harith Azidin Kamarudin. (2014). Impak Penggunaan Multimedia Dalam Pengajaran

Topik Isometrik Terhadap Pencapaian Dan Motivasi Pelajar Tingkatan 2. Tesis

Sarjana. Johor. Universiti Tun Hussein Onn Malaysia

Johnson, D., (1994). Research Methods in Educational Management. Longman Group, Essex.

Kementerian Pelajaran Malaysia. (2012). Laporan Awal Pelan Pembangunan

Pendidikan Malaysia: http://www.moe.gov.my/userfiles/file/PPP/PreliminaryBlueprint BM.pdf.

Mat Nor Hussin, Ab. Rahman Ab. Rashid. (1988). Alat Bantu Mengajar Dalam Pengajaran Bahasa, Siri Pendidikan Longman, Selangor, Longman Malaysia Snd. Bhd.

Mohd Aris Othman. (2007). Keberkesanan Kaedah Pengajaran Berbantukan Komputer Di Kalangan Pelajar Pencapaian Akademik Rendah Bagi Mata Pelajaran Geografi Tingkatan 4 di Negeri Sembilan. Universiti Sains Malaysia.

Mohd Dahlan Mohd Ramli. (1992). Keberkesanan Penggunaan Alat dan Bahan

Mengajar Peserta-peserta KPK Dalam Pengajaran dan Pembelajaran: Satu Tinjauan. Mei (4) Jurnal Guru m.s. 270 -280.

Mohd Najib Abdul Ghafar (1999). Penyelidikan Pendidikan, Edisi Pertama. Skudai: Universiti Teknologi Malaysia.

Mok Song Sang, (1986). Pengajaran dan pembelajaran matematik untuk peringkat sekolah rendah. Longman, Petaling Jaya, Selangor.

Ng Ying Shya (2004). Penggunaan Alat Bantu Mengajar Di Kalangan GuruGuru Teknikal Sekolah Menengah Teknik, Negeri Kedah. Universiti Teknologi Malaysia: Tesis Sarjana Muda.

Noor Azlan Ahmad Zanzali dan Nurdalina Daud. (2009). Penggunaan Bahan Bantu Mengajar Di Kalangan Guru Pelatih UTM Yang Mengajar Matapelajaran Matematik. pp. 1-6. (Unpublished).

Noor Saliza \& Zulkafli Mohd Yusof. (2005). Permasalahan akademik pelajar di Universiti Teknologi MARA: Kajian pengenalan. 3rd International Seminar on Learning and Motivation: Enhancing Student Engagement. Malaysia, Langkawi. Noraziah Abdul Hamid. (1981). Alatan Mengajar dalam Pengajaran Bahasa Malaysia. Dalam Seminar Perguruan Dis. 1981. Universiti Malaysia. Hlm. 2630.

Noriati A. Rashid. (2009). Murid Dan Alam Belajar. Oxford Fajar.Shah Alam Selangor. 
Norma Hassan (2004). Hubungan Di Antara Penggunaan Bahan Bantu Mengajar Dengan Minat Pelajar Tahun Lima Di Sekolah Kebangsaan Kem, Pengkalan Chepa, Kelantan. Satu kajian. Tesis Ijazah Sarjana Muda, UPSI.

Omardin Ashaari (1999). Pengajaran Kreatif untuk Pembelajaran Aktif. Kuala Lumpur: Dewan Bahasa dan Pustaka.

Piaget J (1952). The origins of intelligence in children. New York: International Universities press.

Rashidi Azizan dan Adbul Razak Habib. (1998). Pengajaran Dalam Bilik Darjah Kaedah dan Strategi. Masa Enterprise. Kajang. Selangor.

Ruhaidah, Hamdan. (2011). Penggunaan bahan bantu mengajar dalam pengajaran kemahiran asas membaca di kelas pemulihan khas murid tahun tiga di daerah Kota Marudu. Masters thesis, Universiti Utara Malaysia.

Sabitha Marican. (2005). Kaedah Penyelidikan Sosial. Edisi Pertama Petaling Jaya: Prentice Hall Pearson Malaysia.

Sekaran, Uma (1992). Research Methods for Business: Skill Building Approach;2nd Edition, John Wiley \& Sons, Inc.

Shaffe Hj. Mohd Daud (1990). Masalah Penggunaan Pusat Sumber di SekolahSekolah Menengah Daerah Kota Tinggi. Projek Sarjana Muda, Universiti Teknologi Malaysia.

Shanmugam, Segaran (1999). Penggunaan Bahan Pengajaran dan Pembelajaran dalam Bilik Darjah di Sekolah-Sekolah Menengah di Daerah Port Dickson, Negeri Sembilan. Masters project report, Universiti Putra Malaysia.

Slavin, Robert E. (1997). Educational Psychology: Theory and Practice, 5th. Allyn \& Bacon, Boston, MA.

Sulaiman Ngah Razali (1996). Analisis Data Dalam Penyelidikan. Kuala Lumpur: Dewan Bahasa dan Pustaka.

Tengku Zawawi Tengku Zainal, Ramlee Mustapha \& Abdul Razak Habib. (2009). Pengetahuan Pedagogi Isi Kandungan Guru Matematik bagi Tajuk Pecahan: Kajian Kes di Sekolah Rendah. Jurnal Pendidikan Malaysia 34(1): 131 - 153.

Wiersma, W. (1995). Research Methods in Education: An Introduction, 6th. ed. Massachusetts: Allyn and Bacon. 